\title{
Indispensable Measuring Techniques for Water Relations of Plants and Soils: A Review
}

\author{
Eman F. A. Awad-Allah \\ Soil and Water Sciences Department, Faculty of Agriculture, Alexandria University, Alexandria, Egypt \\ Email: eman.awadallah@alexu.edu.eg
}

How to cite this paper: Awad-Allah, E.F.A. (2020) Indispensable Measuring Techniques for Water Relations of Plants and Soils: A Review. Open Journal of Soil Science, 10, 616-630. https://doi.org/10.4236/ojss.2020.1012030

Received: October 25, 2020

Accepted: December 28, 2020

Published: December 31, 2020

Copyright $\odot 2020$ by author(s) and Scientific Research Publishing Inc. This work is licensed under the Creative Commons Attribution International License (CC BY 4.0).

http://creativecommons.org/licenses/by/4.0/

(c) (i) Open Access

\begin{abstract}
Water is essential for the existence of all living forms on the earth, and the kinds and amounts of vegetation occurring on various parts of the earth's surface depend more on the quantity of water available than on any other single environmental factor. Therefore, the need for the non-subjective, diagnostic assessment tools for water status measurements of plants and soils is indispensable to avoid water shortage problems and achieve sustainable development goals (SDGs) of agricultural sector. The best measure of the energy status of water in plants and soils is the water potential $\left(\Psi_{w}\right)$, which has the advantage of being physically defined and the force that causes water movement. There are many different instruments that have essential roles for measuring water status of plant, for example, Pressure Chamber, Isopiestic Psychrometer, Pressure Probe, and Osmometers. Each had the ability to indicate not only the water status of various parts of plants and soils but also the forces used to move water from place to place. Nowadays, speaking plant approach (SPA) identifies the optimal crop cultivation conditions based on the physiological status of the plants. The physiological status information from a living plant can be achieved by using a chlorophyll fluorescence imaging robot, which is a powerful tool for early detection of drought stress in plants under practical production greenhouse conditions. Moreover, recently thermal imaging and remote sensing technology are both feasible for precise irrigation guidance and precision water management.
\end{abstract}

\section{Keywords}

Isopiestic Psychrometer, Pressure Probe, Pressure Chamber, Osmometers, Chlorophyll Fluorescence Imaging, Thermal Imaging, Precision Agriculture

\section{Introduction}

Water scarcity is a destructive phenomenon for the whole living forms on the 
earth's surface. Water is essential for the existence of life, and the kinds and amounts of vegetation occurring on various parts of the earth's surface depend more on the quantity of water available than on any other single environmental factor [1]. The distribution of plants over the earth's surface is controlled by water and temperature, and where temperature permits plants to grow, chiefly by the quantity and distribution of precipitation [1] [2].

Nowadays the problem of water shortage needed for crop production is common worldwide especially in countries of the arid and semiarid regions [3] [4]. This leads to limited food production for humans and animals. The world's demand for water is likely to surge in the next few decades. Rapidly growing populations will drive increased water consumption by people and farms Table 1. According to the United Nations, the world's population could increase by $50 \%$ during the next 45 years to reach 9 billion inhabitants by 2050 .

Table 1. Projections of world population (billion).

\begin{tabular}{cccc}
\hline Year & More developed region & Less developed region & Total World \\
\hline 2010 & 1.23 & 5.67 & 6.91 \\
2020 & 1.25 & 6.41 & 7.67 \\
2030 & 1.26 & 7.06 & 8.34 \\
2040 & 1.25 & 7.57 & 8.82 \\
2050 & 1.25 & 7.94 & 9.19 \\
\hline
\end{tabular}

Source: United Nations.

Stress is considered to be a significant deviation from optimal conditions of life. Plants are persistently challenged by a wide spectrum of biotic and abiotic stresses because of unavoidable environmental conditions which adversely affect their growth and development [5] [6]. Abiotic stress is the primary cause of crop loss worldwide, causing average yield losses of more than $50 \%$ for major crops [7]. Drought is one of main abiotic stresses causing considerable losses in the productivity of many crops every year worldwide, while the demand for food and energy is on the rise [8]. Presently it is estimated that one-third of the land, potentially usable for agriculture, is not cultivated because of deficient water availability, and most of the remaining land yields are periodically reduced by drought [7].

Exposure of plants to a water-limiting environment during various developmental stages appears to activate a diverse set of physiological, metabolic and defense systems to survive and to sustain growth [3]. Tolerance and susceptibility to abiotic stresses are very complex. To develop crop plants with enhanced tolerance of drought stress, a basic understanding of biochemical and molecular mechanisms, physiological and metabolic aspects of stress tolerance is crucial and still a major challenge in biology to facilitate the development of crops with an inherent capacity to withstand abiotic stresses [5] [6] [8].

Many investigators aim to improve crop production under drought stress through selection of certain cultivars which can tolerate drought conditions. In this concern, seeking nutritional balance can also boost crop growth and stimu- 
late regulatory tolerant mechanisms of dehydration suppression during water deficit stress [9]. Nowadays employing contemporary tools and techniques from all branches of science is essential to understand how plants respond to abiotic stresses with the aim to help manipulate plant performance that will be better suited to withstand these stresses. This would help stabilize the crop production, and significantly contribute to food and nutritional security in developing countries and semi-arid tropical regions [10]. Therefore, the need for the non-subjective, diagnostic assessment tools of water status measurements of plants and soils is indispensable to avoid water shortage problems and achieve sustainable development goals (SDGs) of agricultural sector.

\section{Plant and Water Relations}

Water is the most abundant constituent of all physiologically active plant cells, ranging between $55 \%-85 \%$ of the water content of leaves [11]. The great bulk of the water in any plant constitutes a unit system. This water is not in a static condition. Rather it is part of a hydrodynamic system, which in terrestrial plants involves absorption of water from the soil, its translocation throughout the plant, and its loss to the environment, principally in the process known as transpiration [1]. The best measure of the energy status of water in plants and soil is the water potential $\left(\Psi_{w}\right)$, which is the amount by which its chemical potential is reduced below that of pure water Equation (2.1):

$$
\Psi_{w}=\text { Water Potential }=\frac{\mu_{w}-\mu_{o}}{\overline{V_{w}}}=\frac{R T}{\overline{V_{w}}} \ln a_{w}
$$

where:

$\mu_{w}=$ Chemical potential of water in cell (energy per mol), $\mu_{o}=$ Chemical potential of pure free water (energy per mol), $V_{w}=$ Partial molal volume of water (volume per mol), $R=$ Gas constant (energy $\cdot \mathrm{mol}^{-1} \cdot \mathrm{K}^{-1}$ ), $T=\operatorname{Kelvin}(\mathrm{K}), a_{w}=$ Water activity controlled by solute, pressure, matrix, and gravity (no units).

The water potential has the advantage of being physically defined and the force that causes water movement. Thus, the water potential is a better indication of plant water status [1]. Water potential is the sum of all forces acting on the water. Accordingly, the components of the water potential are:

$$
\Psi_{w}=\Psi_{s}+\Psi_{p}+\Psi_{m}+\Psi_{g}
$$

where the subscripts $s, p, m$, and $g$ represent the effects of solute, pressure, matrix, and gravity, respectively. For most of our purposes, gravitational potentials will be ignored because they become significant only at heights greater than 1 meter in vertical water columns. In these cases, Equation (2.2) reduces to:

$$
\Psi_{w}=\Psi_{s}+\Psi_{p}+\Psi_{m}
$$

Water in plants generally has a negative $\Psi_{w}$ because $\Psi_{s}$ and $\Psi_{m}$ are negative and $\Psi_{p}$ does not fully compensate for them. Water will move toward more negative $\Psi_{W}$ or more negative components of $\Psi_{W}$ and plants use this principle to extract water from the soil [12]. 
Plant water is located in two compartments separated by a differentially permeable membrane. The first compartment is the interior of the cells (the protoplasts which collectively are the symplast) and the second is the cell walls and xylem outside of the protoplasts (collectively the apoplast) [12].

In the protoplast compartment (Pro), there is a concentrated solution ( $\left.\Psi_{s}^{\text {Pro }}\right)$, usually a pressure above atmospheric $\left(\Psi_{p}^{\mathrm{Pro}}\right)$ and matric potential is generally negligible $\left(\Psi_{m}^{\text {Pro }}=0\right)$ so that water potential $\left(\Psi_{w}^{\text {Pro }}\right)$ is:

$$
\Psi_{w}^{\text {Pro }}=\Psi_{s}^{\text {Pro }}+\Psi_{p}^{\text {Pro }}
$$

In the apoplast compartment (apo), there is no turgor and generally a dilute solution ( $\Psi_{s}^{\mathrm{apo}}$ ) and a porous matrix of the cell walls generate a matric potential $\left(\Psi_{m}^{\mathrm{apo}}\right)$. These components are expressed by:

$$
\Psi_{w}^{\mathrm{apo}}=\Psi_{s}^{\mathrm{apo}}+\Psi_{m}^{\mathrm{apo}}
$$

The water potential in each protoplast is almost the same as in its own cell wall [12] [13] [14] [15] and it is described as:

$$
\Psi_{s}^{\text {apo }}+\Psi_{m}^{\text {apo }}=\Psi_{s}^{\text {Pro }}+\Psi_{p}^{\text {Pro }}
$$

This shows that the components of the water potential in the protoplasts $\left(\Psi_{s}^{\text {Pro }}+\Psi_{p}^{\text {Pro }}\right)$ are different from those in the apoplast $\left(\Psi_{s}^{\text {apo }}+\Psi_{m}^{\text {apo }}\right)$ but they balance each other locally [12] [14] [15].

\section{Water Status Measurements in Plants and Soils}

Plant water status can be estimated from visual symptoms or measured quantitatively in terms of water content or free energy status, the water potential [15]. Consideration of the method to be used depends on the reasons for measuring it. The various reasons for measuring plant water status are to determine when to irrigate, to screen plant populations, to study effects of water stress on growth and yield, and to study effects of water stress on physiological an biochemical processes [16].

Methods of measuring plant water status can be classified in three categories [12]. Those in the first category rely on concentrated solutions (osmotica) that cause water release from the tissue. Placing roots in a series of osmotica can indicate which solution causes no water loss or gain, or which causes no change in tissue dimensions. The water status is then expressed in terms of the solution properties causing no change. While these are relatively simple methods and have some limitations such as the possibility of solute exchange with the tissue. Also, tissue can release water and solute that can change conditions in the osmoticum. Therefore, these methods are not often used. The second category is based on measures of plant water content that are informative when compared to other tissue properties. The third category is based on thermodynamic methods that determine the chemical potential of water in the tissue. These methods have the advantage that the water status is compared to a physically defined reference rather than a biological one, and the physical reference allows the 
chemical potential to be precisely reproduced at any time or place [12] [16].

There are many different instruments that have essential roles for measuring water status of plant. For example, pressure chamber was proposed to measure the tension in the xylem and apoplast of plants. Other methods employed vapor pressures to measure the water potential and were simplified and made more accurate such as Isopiestic Psychrometer [17]. A microcapillary method was developed for directly measuring the turgor inside individual cells such as Pressure Probe. Each had the ability to indicate not only the water status of various parts of plants and soils but also the forces used to move water from place to place [12].

\subsection{Isopiestic Psychrometers}

Thermocouple psychrometry is the most widely used method of measuring plant water status and probably is the most versatile. It can measure the water status of any plant part as well as soil or any substance containing water [12].

Measurements of the water potential of plant tissue Figure 1 and Figure 2 are made with thermocouple psychrometers by enclosing the tissue and thermocouple in a small container kept at a constant temperature and determining the degree of cooling of the thermocouple as water evaporates from it and is absorbed by the tissue. It is assumed that the rate of vapor transfer is proportional to the difference in potential between the thermocouple and plant material [12] [17]. Isopiestic means equal pressure and isopiestic psychrometers determine the vapor pressure of a known solution that equals the vapor pressure of the unknown [12] [17].

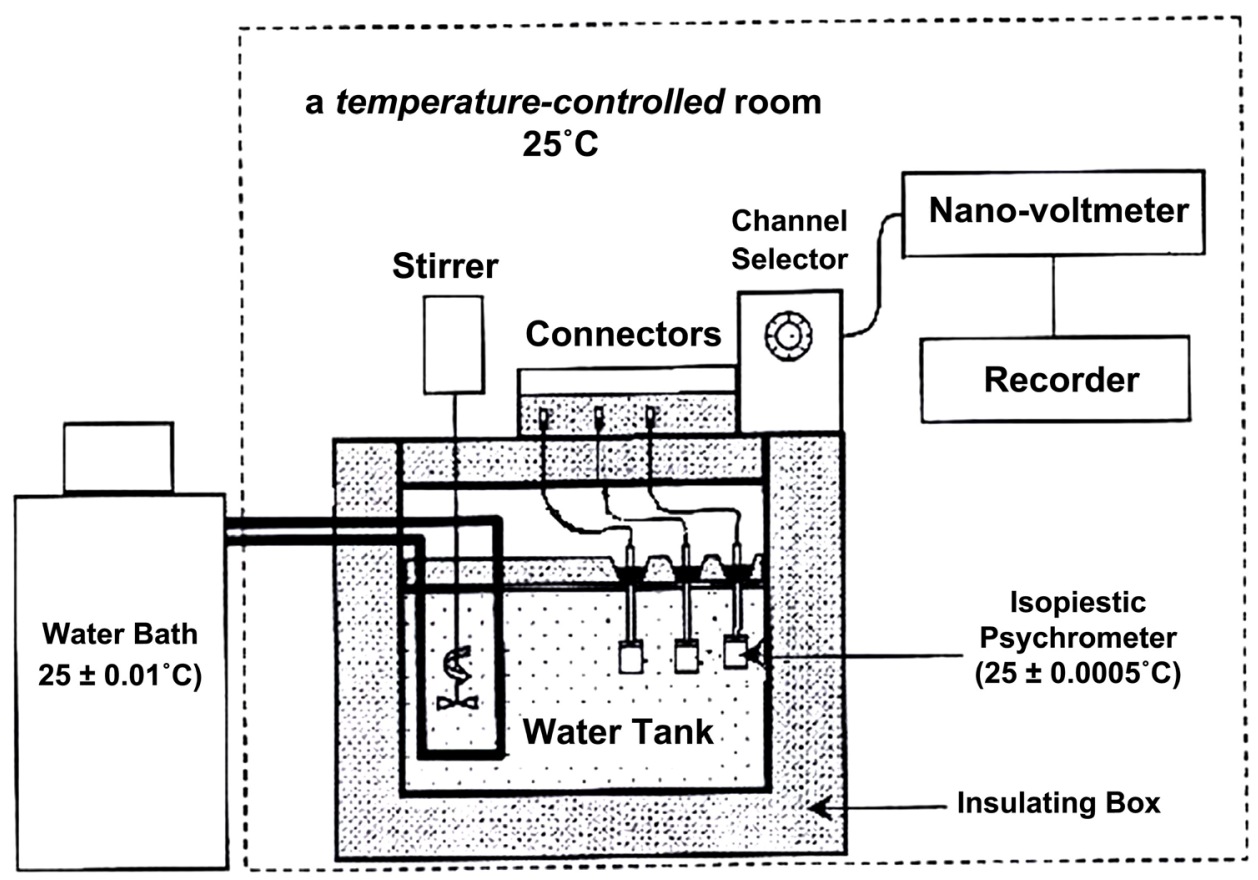

Figure 1. Layout of Isopiestic Psychrometer and controlled surrounding systems of the measurement. Adapted from Wada [14], as cited in Awad-Allah [15]. 


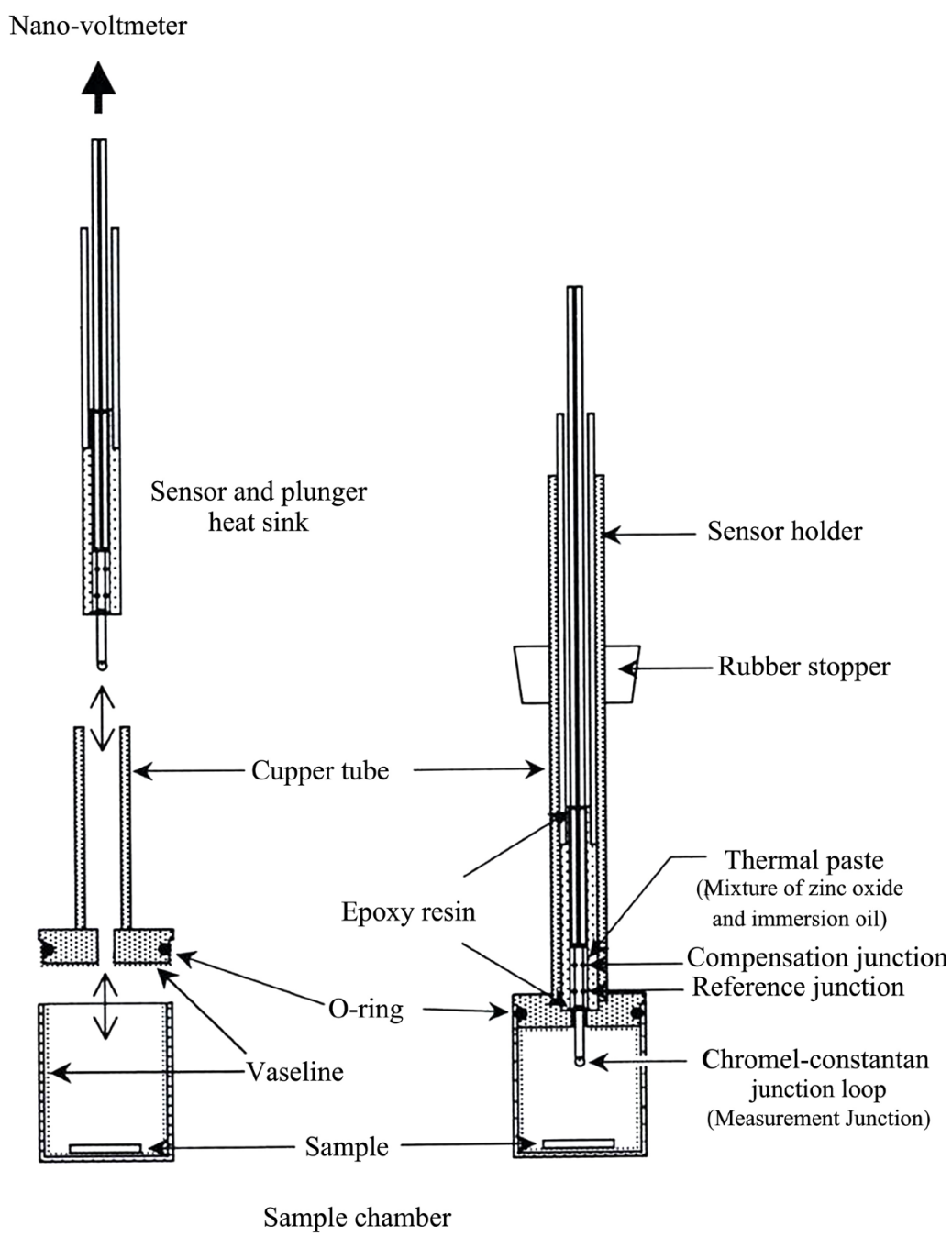

Figure 2. Schematic diagram of Isopiestic Psychrometer. Wada [14], as cited in Awad-Allah [15].

Figure 1 showed the Layout of Isopiestic Psychrometer with controlled surrounding systems of the measurement, adapted from Wada [14], as cited in Awad-Allah [15]. Air temperature in the room surrounding Isopiestic psychrometers was controlled at $25^{\circ} \mathrm{C}$ and the water bath was set at $25^{\circ} \mathrm{C} \pm 0.01^{\circ} \mathrm{C}$, and thus the measurements can be conducted at $25^{\circ} \mathrm{C} \pm 0.0005^{\circ} \mathrm{C}$ water tank was covered with thick insulation and water in the tank was stirred.

Figure 2 explained schematic diagram of Isopiestic Psychrometer, Wada [14], as cited in Awad-Allah [15]. Before measurement, thermocouple should be cleaned with a water rinse and dry in an air stream. Vapor chamber should be coated with Vaseline by warming the cup to melt Vaseline, then covering the bottom and walls and inverting to cool. For isopiestic psychrometers, the hole through which the thermocouple enters the chamber should be coated by wiping Vaseline into the hole, then removing the excess with a spatula that leaves only a thin coating. Rapidly the sample should be loaded into the cleaned and Vaseline coated cup. The sample should be pressed into the Vaseline layer at two or three places to ensure good thermal drainage of metabolic heat to the chamber walls. 
Loading and sealing the cup should take no longer than 10 sec to avoid dehydrating the tissue. If longer sampling times are required, work should be done in a saturated atmosphere. High humidity can be achieved by constructing a simple glove box [12] [14].

For isopiestic psychrometers, the water potential can be formalized with the following equation. Let $T C_{h}$ be the steady voltage displayed by the thermocouple with the known solution at the higher potential $\left(\Psi_{h}\right.$, closest to 0$), T C_{l}$ be the steady voltage displayed by the thermocouple with the solution at the lower potential $\left(\Psi_{l}\right)$, and $T C_{d}$ be the steady voltage of the dry thermocouple [12]. The solution that gives the output of the dry thermocouple is the isopiestic value and is calculated from:

$$
\frac{T C_{h}-T C_{d}}{T C_{h}-T C_{l}} \cdot\left(\Psi_{l}-\Psi_{h}\right)+\Psi_{h}=\text { isopiestic value }
$$

After measuring water potential, Isopiestic psychrometers can also be used for measuring osmotic potential of the tissue by freezing at $-70^{\circ} \mathrm{C}$ and thawing at $25^{\circ} \mathrm{C}[12][13][18]$.

\subsection{Pressure Probe}

The pressure probe is the only instrument that can measure the water status of single cells. It consists of a transducer that monitors the pressure in an oil-filled microcapillary whose microscopic tip is inserted into a cell. The pressure necessary to prevent cytoplasm from entering the microcapillary equals the turgor pressure $\left(\Psi_{p}\right)$ of the cell [12] [19]. The accurate measurement of turgor $\left(\Psi_{p}\right)$ is essential for understanding physiological processes such as osmoregulation, cell expansion, and stomatal opening [19].

The pressure of cell can be measured by puncturing the cell wall and with a sharpened tip of a microcapillary Figure 3(A) and Figure 3(B). When the tip enters the cell, the pressure in the cell pushes cytoplasm into the oil-filled microcapillary. The cytoplasm is pushed back into the cell with a metal rod that is forced into the oil, raising its pressure. As the pressure in the microcapillary rises, the cytoplasm is completely returned to the cell and the cytoplasm/oil meniscus is at its original position before puncturing. The pressure in the microcapillary is then the same as the pressure in the cell and is indicated by a pressure transducer [15].

\section{Pressure Probe and Isopiestic Psychrometer Measure Similar Turgor} Turgor pressure $\left(\Psi_{p}\right)$ can be measured by using either the isopiestic psychrometer or the pressure probe [15] [19] [21]. Measuring turgor pressure is important for understanding physiological processes such as osmoregulation, cell expansion, and stomatal opening [19].

The miniature pressure probe has the ability to measure turgor directly in the single cells of higher plants Figure 3(B). When care was taken to prevent dehydration during working with the pressure probe, and diffusive resistance and 


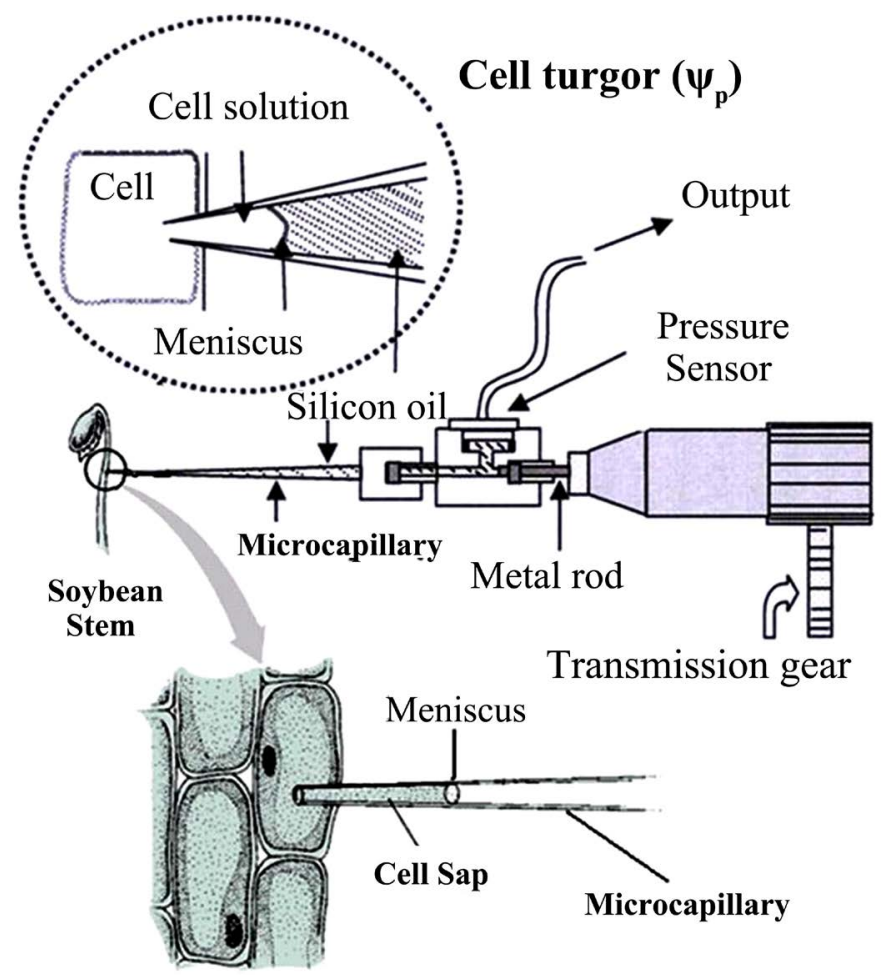

Figure 3(A). Schematic diagrams of pressure probe for measuring turgor pressure of elongation zone of soybean hypocotyl. Adapted from Hossain [20], as cited in Awad-Allah [15].

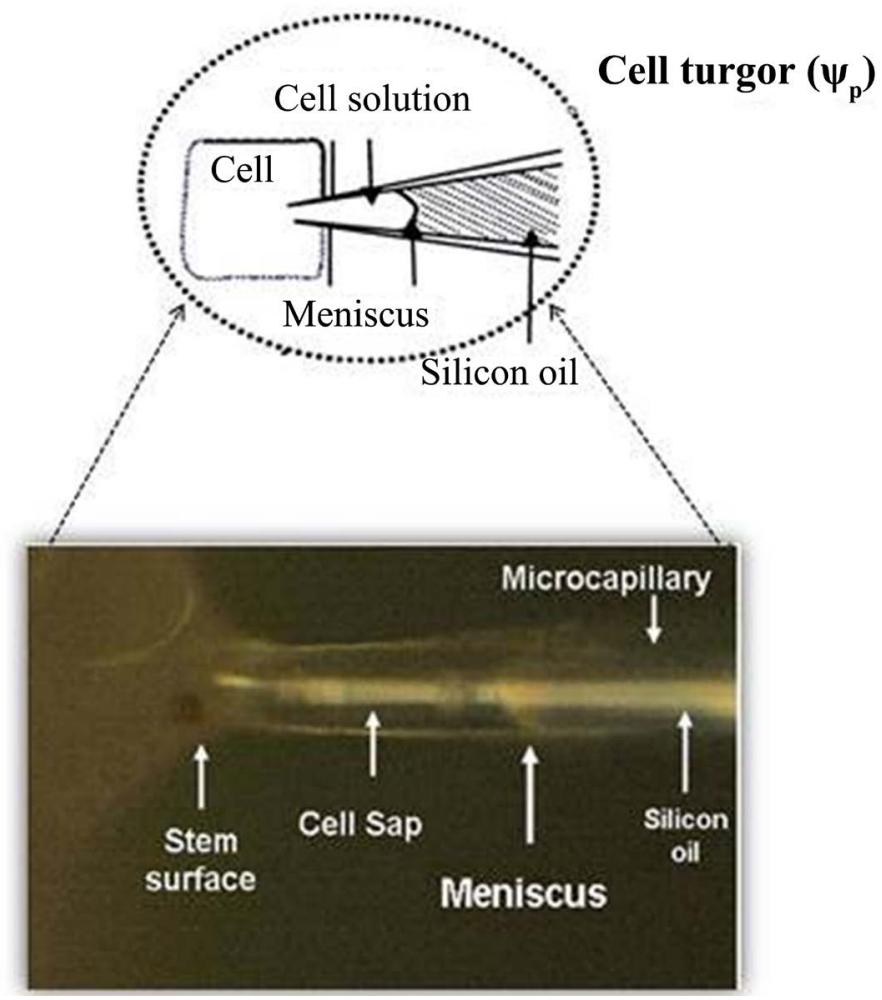

Figure 3(B). Photo of a microcapillary of the pressure probe which was inserted in a single cell, having the meniscus between cell sap and the silicon oil during measuring turgor pressure. The operation was monitored under a digital microscope (VHX-900 digital microscope, Keyence Co., Osaka, Japan) which facilitated recording the experiment. Awad-Allah [15]. 
dilution errors with the psychrometer, both methods gave similar values of turgor whether the plants were dehydrating or rehydrating [15] [19]. This indicates that the pressure probe gives accurate measurements of turgor despite the need to penetrate the cell. It also suggests that as long as precautions are taken to obtain accurate values for the water potential and osmotic potential, turgor can be determined by isopiestic psychrometry in tissues not easy to measure with pressure probe for physical reasons [15] [19] [21].

\subsection{Pressure Chamber}

Pressure chambers are the most widely used field instruments for measuring plant water status [12]. They are affordable, portable, allow rapid and easy measurements. Moreover, temperature needs little control and no complex instrumentation is required.

Pressure chamber was proposed to measure the tension in the xylem and apoplast of plants. Figure 4 shows measuring water potential with a pressure chamber. A cut branch (or leaf or compound leaf) is placed inside the chamber, with the cut end protruding from the seal. The seal gives an airtight barrier between the interior and the atmospheric pressure outside [12]. Once the chamber has been sealed, the pressure is gradually applied from the compressed gas cylinder [22]. This allows the tissue to be pressurized inside, forcing water toward the outside. The pressure necessary to hold the water at the outside surface measures the water status of the tissue. The more dehydrated the tissue, the more pressure is required [12] [22].

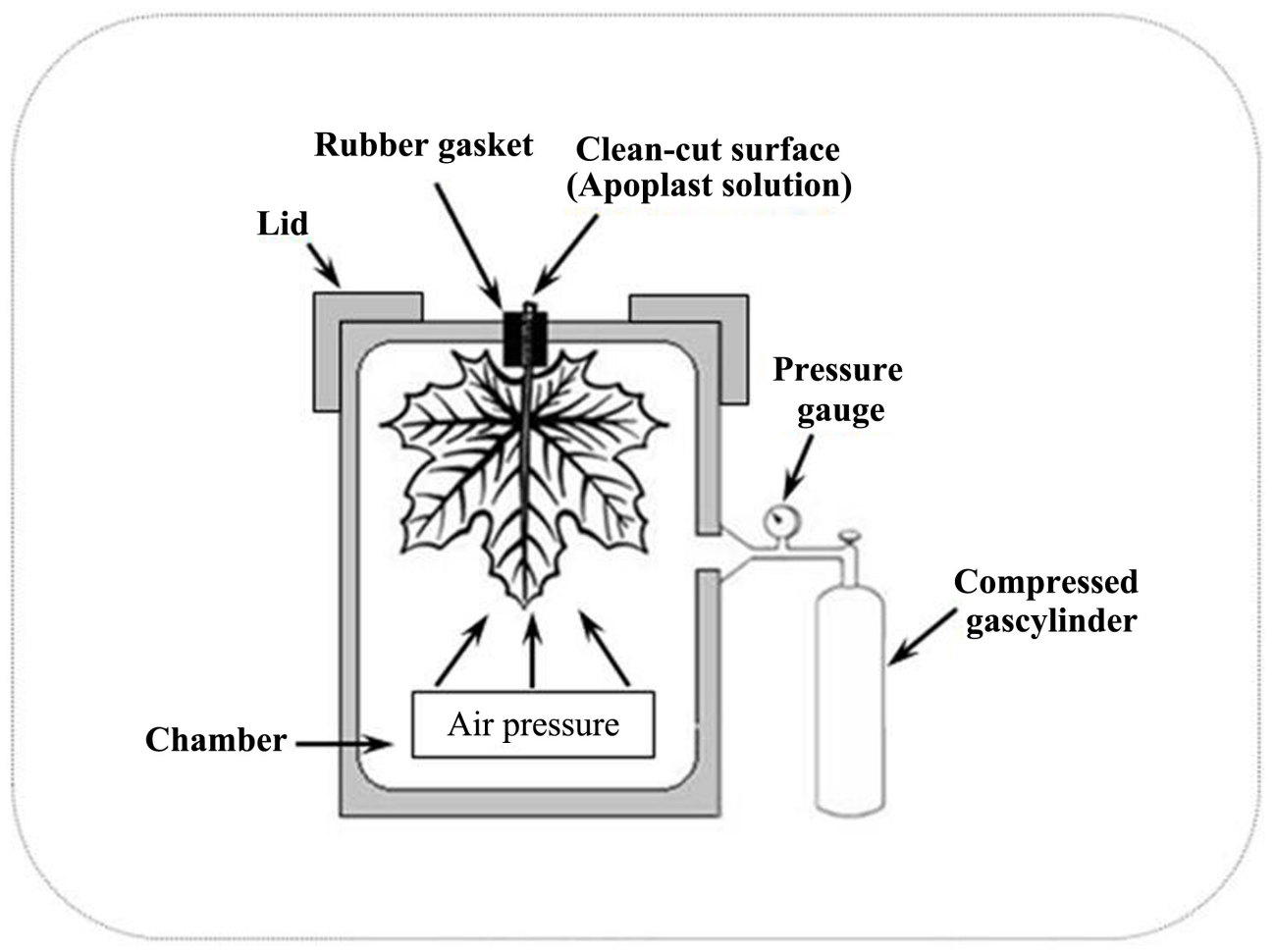

Figure 4. Basic layout of pressure chamber design used for measuring plant water potential. 


\subsection{Osmometers}

Osmometers are used to measure osmotic potential $\left(\Psi_{\pi}\right)$ in plant water relations by measuring its freezing point [2] [23]. The pressure probe, which is routinely used to measure the turgor potential turgor pressure $\left(\Psi_{p}\right)$ of individual epidermal plant cells, has also been used to sample small volumes of vacuolar fluid from these same cells (as small as $0.02 \mathrm{nl}$ ) for measurement of cellular solute (osmotic) potential $\left(\Psi_{\pi}\right)$ in a micro freezing point osmometer [23]. The freezing point depression method is the most commonly used method in laboratories around the world.

The measurement principle is built on the colligative property of freezing-point depression of a solution [24]. Solutions have colligative properties that collectively depend on the number of dissolved particles and not on the nature of the solute. For example, solutes reduce the vapor pressure of a solution, raise its boiling point, and lower its freezing point [25]. This effect depends solely on the number of particles in the liquid and not on the physical or chemical properties of the solutes. One of the colligative properties of solutions is the decrease in the freezing point as the solute concentration increases. For example, the freezing point of the solution will decrease on adding a solute to a liquid. Therefore, a solution containing $1 \mathrm{~mol}$ of solutes per kilogram of water has a freezing point of $-1.86^{\circ} \mathrm{C}$, compared with $0^{\circ} \mathrm{C}$ for pure water. Due to this linear correlation, the osmolality of a sample can be determined by precisely measuring its freezing point [24].

\section{The Future of Water Relations of Plants}

\subsection{Speaking Plant Approach (SPA) Technique for Intelligent Greenhouse}

The speaking plant approach (SPA) is becoming an indispensable concept for environmental control in highly sophisticated greenhouses to maximize profit of agricultural production [26] [27]. An important feature of SPA is sensor-based plant diagnostic techniques, which are used to monitor plant physiological status [26]. The first and most important step in the SPA is to obtain physiological information from a living plant and then to judge whether the plant is healthy [28]. Two prospective plant diagnostic techniques can be utilized for the SPA in greenhouses [26]. The first technique is plant diagnosis based on a plant's odor. Plants emit a broad range of volatile organic compounds and a plant's emission profile changes depending on its physiological status [26]. The second technique is chlorophyll fluorescence imaging. This technique measures the chlorophyll fluorescence induction phenomenon a dynamic change in chlorophyll fluorescence intensity induced by illuminating a dark-adapted leaf with a stable intensity excitation light and analyzes the shape of the induction curve [26] [28] [29].

The chlorophyll fluorescence imaging robot is useful diagnostic technique for evaluating photosynthetic functions of plants without actually touching the plant [26] [28]. Chlorophyll fluorescence imaging robot has been used to evaluate the 
heterogeneous distribution of photosynthetic activities over a leaf surface and has thus been applied to the detection of photosynthetic dysfunctions caused by biotic and abiotic stress factors [26] [28] [29]. The developed chlorophyll fluorescence imaging robot is expected to be implemented in commercial tomato production greenhouse in the near future [29]. Takayama et al. [28] reported that chlorophyll fluorescence induction imaging system is a powerful tool for early detection of drought stress in tomato plants under practical tomato production greenhouse conditions.

\subsection{Thermographic Imaging for the Study of Plant-Water Relations}

Several useful application of infrared thermography in plant and crop science, for example as a diagnostic tool for plant water relations, a number of plant diseases and environmental pollutants, also depend on the indirect effects of these stressors on stomatal aperture and transpiration rate [30]. Whereas, increases in leaf temperature detected by thermography largely reflect stomatal closure as a measure of stress [30].

The usage of infrared thermal imaging for the study of environmental and physiological responses of both single plants and whole crops is common; especially thermography is becoming affordable, readily portable, and feasible to diagnose different environmental abiotic or biotic stresses [30]. Future research should aim at applicable use of thermal imaging as irrigation scheduling tool for precise mapping the water status of different crops.

Benavente et al. [31] studied thermographic imaging as assessment tool of drought and heat tolerance in spanish germplasm of Brachypodium distachyon. The results suggested that thermographic images were able to distinguish between soil and leaf temperature in the stressed and control plants. Also, adaptation response of these species to drought is linked to more efficient stomata regulation. So, under water stress stomata of more tolerant genotypes are closed, increasing foliar temperature and water use efficiency by reducing transpiration. Under water availability, it seems that opening stomata allow plants to increase transpiration and therefore to diminish foliar temperature.

\subsection{Remote Sensing of Plant-Water Relations}

Agriculture faces the challenge of feeding a growing population with limited or depleting fresh water resources. Advances in irrigation systems and technologies allow site-specific application of irrigation water within the field to improve water use efficiency or reduce water usage for sustainable crop production, especially in arid and semi-arid regions [32].

Site-specific management can be thought of as a series of layers of information about each field. Each time a measurement is made (soil tests, scouting reports, yield data, etc.), another layer of information is added [32] [33]. Over time, multiple layers of information are added and become part of the database that can guide future crop management decisions. Also, one of the basic principles of the 
concept of precision agriculture is to fit resources to needs, according to temporal and spatial variability in the field [34]. Therefore, irrigating according to the principle of precision agriculture may improve water distribution in the specific field [32] [33].

Water requirement varies with the crop growth and development, soil water status, as well as environmental conditions. Closely monitoring soil water status, crop growth conditions and their spatial and temporal patterns can aid in irrigation scheduling and precise water management [32] [33]. The first step in the process is to map the variability in the water status of the plants in the field. Among many tools, remote sensing can serve an effective basis by providing images with spatial and temporal variability of crop growth parameters and soil moisture status for input in precision water management. This tool enhances the ability to fine-tune management decisions and develop the site-specific water management plan for each field [32]. This explains the importance of remote sensing as a low-cost tool to improve water and nutrient management in crops [32] [33].

\section{Conclusions and Future Perspectives}

Plants are persistently challenged by a wide spectrum of biotic and abiotic stresses which adversely affect their growth and development. Nowadays employing contemporary tools and techniques is essential to understand how plants respond to abiotic stresses with the aim to help manipulate plant performance that will be better suited to withstand these stresses. Therefore, the need for the non-subjective, diagnostic assessment tools of water status measurements of plants and soils is indispensable to avoid water shortage problems and achieve sustainable development goals (SDGs) of agricultural sector. There are many measuring techniques that have essential roles for measuring water status of plant, for example, Pressure Chamber, Isopiestic Psychrometer, Pressure Probe, and Osmometers. Each had the ability to indicate not only the water status of various parts of plants and soils but also the forces used to move water from place to place.

Recently, the chlorophyll fluorescence imaging technique is useful for early detection of subtle changes or trends in plant health long before they're visible to the human eye by using the speaking plant approach (SPA) in a greenhouse. Thus, the developed chlorophyll fluorescence imaging technique is expected to be implemented in greenhouse commercial production in the near future. Moreover, precise irrigation guidance and precision water management can be achieved by using feasible diagnostic assessment tools such as infrared thermal imaging and remote sensing technology for sustainable production.

\section{Acknowledgements}

I would like to express my sincere gratitude and appreciation to Prof. Dr. Hiroshi Nonami, a Professor of the Department of Bio-mechanical System, Faculty of 
Agriculture, Ehime University, Japan, for making most of water relations measuring techniques available for researchers, post-graduate, and under-graduate students at Plant Biophysics/Biochemistry Research Laboratory.

\section{Conflicts of Interest}

The author declares no conflicts of interest regarding the publication of this paper.

\section{References}

[1] Kramer, P.J. and Boyer, J.S. (1995) Water Relations of Plants and Soils. Academic Press, San Diego.

[2] Kramer, P.J. (1983) 2-Water Relations of Plants. In: Kramer, P.J., Ed., Water Relations of Plants, Academic Press, Inc., San Diego, 23-56. https://doi.org/10.1016/B978-0-12-425040-6.50005-9

[3] Awad-Allah, E.F.A., Gholipour, Y. and Nonami, H. (2012) Growth Promotion with Osmotic Adjustment at Low Water Potentials after $\mathrm{H}_{2} \mathrm{O}_{2}$ Pretreatment in Soybean Seeds. Environmental Control in Biology, 50, 263-276.

[4] Awad-Allah, E.F.A., Gholipour, Y., Nonami, H. and Erra-Balsells, R. (2011) Enhancing Soybean Germination in Arid Areas with $\mathrm{H}_{2} \mathrm{O}_{2}$ Pretreatment. CIGR International Symposium on "Sustainable Bioproduction-Water, Energy, and Food", Tokyo, 19-23 September 2011, 1-5.

[5] Hung, S., Yu C. and Lin, C.H. (2005) Hydrogen Peroxide Functions as a Stress Signal in Plants. Botanical bulletin of Academia Sinica, 46, 1-10.

[6] Kaur, N. and Gupta, A.K. (2005) Signal Transduction Pathways under Abiotic Stresses in Plants. Current Science, 88, 1771-1780.

[7] Ishibashi, Y., Yamaguchi, H., Yuasa, T., Iwaya-Inoue, M., Arima, S. and Zheng, S. (2011) Hydrogen Peroxide Spraying Alleviates Drought Stress in Soybean Plants. Journal of Plant Physiology, 168, 1562-1567. https://doi.org/10.1016/j.jplph.2011.02.003

[8] Valliyodan, B. and Nguyen, H.T. (2006) Understanding Regulatory Networks and Engineering for Enhanced Drought Tolerance in Plants. Current Opinion in Plant Biology, 9, 189-195. https://doi.org/10.1016/j.pbi.2006.01.019

[9] Singh, A., Singh, S. and Prasad, S. M. (2017) Silicon and Nanotechnology Role in Agriculture and Future Perspectives. In: Tripathi, D.K., Singh, V.P., Ahmed. P., Chauhan, D.K. and Prasad, S.M., Eds., Silicon in Plants. Advances and Future Prospects, CRC Press, Taylor \& Francis Group, Boca Raton, 101-116.

[10] Walley, J.W., Coughlan, S., Hudson, M.E., Covington, M.F., Kaspi, R., Banu, G., Harmer, S.L. and Dehesh, K. (2007) Mechanical Stress Induces Biotic and Abiotic Stress Responses via a Novel CIS-Element. PLoS Genetics, 3, e172. https://doi.org/10.1371/journal.pgen.0030172

[11] Hemantaranjan, A. (2016) Plant Stress Tolerance Physiological \& Molecular Strategies. Scientific Publishers, India.

[12] Boyer, J.S. (1995) Measuring the Water Status of Plants and Soils. Academic Press, San Diego.

[13] Nonami, H. and Boyer, J.S. (1987) Origin of Growth-Induced Water Potential: Solute Concentration Is Low in Apoplast of Enlarging Tissues. Plant Physiology, 83, 596-601. https://doi.org/10.1104/pp.83.3.596

[14] Wada, H. (2004) Roles of Water Potential Gradients and Turgor in Cell Elongation, 
Flowering and Bulb Formation. Ph.D. Thesis, Faculty of Agriculture, Ehime University, Matsuyama.

[15] Awad-Allah, E.F.A. (2012) Mechanisms for Drought Tolerance during Germination of Soybean Seeds Pretreated with $\mathrm{H}_{2} \mathrm{O}_{2}$. Ph.D. Thesis, Faculty of Agriculture, Ehime University, Matsuyama.

[16] Kramer, P.J. (1988) Measurement of Plant Water Status: Historical Perspectives and Current Concerns. Irrigation Science, 9, 275-287. https://doi.org/10.1007/BF00296703

[17] Boyer, J.S. and Knipling, E.B. (1965) Isopiestic Technique for Measuring Leaf Water Potentials with a Thermocouple Psychrometer. Proceedings of the National Academy of Sciences of the United States of America, 54, 1044-1051.

[18] Ehlig, C.F. (1962) Measurement of Energy Status of Water in Plants with a Thermocouple Psychrometer. Plant Physiology, 37, 288-290. https://doi.org/10.1104/pp.37.3.288

[19] Nonami, H., Boyer, J.S. and Steudle, E. (1987) Pressure Probe and Isopiestic Psychrometer Measure Similar Turgor. Plant Physiology, 83, 592-595.

https://doi.org/10.1104/pp.83.3.592

[20] Hossain, M.M. (2010) Growth Mechanisms of Tomato Fruit Associated with Water Relations in Leaves and Fruits. Ph. D. Thesis, Faculty of Agriculture, Ehime University, Matsuyama.

[21] Ikeda, T., Nonami, H., Fukuyama, T. and Hashimoto, Y. (1999) Hydraulic Contribution in Cell Elongation of Tissue-Cultured Plants: Growth Retardation Induced by Osmotic and Temperature Stresses and Addition of 2,4-dichlorophenoxyacetic Acid and Benzylaminopurine. Plant, Cell \& Environment, 22, 899-912. https://doi.org/10.1046/j.1365-3040.1999.00463.x

[22] Pérez-Harguindeguy, N., Díaz, S., Garnier, E., Lavorel, S., Poorter, H., Jaureguiberry, P., Bret-Harte, M.S., Cornwell, W.K., et al. (2013) New Handbook for Standardised Measurement of Plant Functional Traits Worldwide. Australian Journal of Botany, 61, 167-234. https://doi.org/10.1071/BT12225

[23] Fisher, D.B. (1985) In Situ Measurement of Plant Water Potentials by Equilibration with Microdroplets of Polyethylene Glycol 8000. Plant Physiology, 79, 270-273. https://doi.org/10.1104/pp.79.1.270 https://www.jstor.org/stable/4269501

[24] Taiz, L., Zeiger, E., Moller, I.M. and Murphy, A. (2015) Plant Physiology and Development. 6th Edition, Sinauer Associates, Sunderland.

[25] Chang, R. (2005) Physical Chemistry for the Biosciences. University Science Books Cop., Sausalito.

[26] Takayama, K. (2013) Second Generation Speaking Plant Approach: Practical Application. Journal of Science and High Technology in Agriculture, 25, 165-174.

[27] Takayama, K. and Nishina, H. (2015) Intelligent Growth Management Based on the Biological Information of Crop. Journal of the Japanese Society for Quality Control, 45, 149.

[28] Takayama, K., Nishina, H., Iyoki, S., Arima, S., Hatou, K., Ueka, Y. and Miyoshi, Y. (2011) Early Detection of Drought Stress in Tomato Plants with Chlorophyll Fluorescence Imaging-Practical Application of the Speaking Plant Approach in a Greenhouse. Proceedings of the 18 th World Congress, the International Federation of Automatic Control, Milano, 28 August-2 September 2011, 1785-1790.

[29] Nishina, H. (2015) Development of Speaking Plant Approach Technique for Intelligent Greenhouse. Agriculture and Agricultural Science Procedia, 3, 9-13. 
https://doi.org/10.1016/j.aaspro.2015.01.004

[30] Jones, H.G. and Leinonen, I. (2003) Thermal Imaging for the Study of Plant Water Relations. Journal of Agricultural Meteorology, 59, 205-217.

[31] Benavente, E., García-Toledano, L., Carrillo, J.M. and Quemada, M. (2013) Thermographic Imaging: Assessment of Drought and Heat Tolerance in Spanish Germplasm of Brachypodium distachyon. Procedia Environmental Sciences, 19, 262-266. https://doi.org/10.1016/j.proenv.2013.06.030

[32] Neupane, J. and Guo, W.X. (2019) Agronomic Basis and Strategies for Precision Water Management: A Review. Agronomy, 9, 87. https://doi.org/10.3390/agronomy9020087

[33] Damm, A., Paul-Limoges, E., Haghighi, E., Simmer, C., Morsdorf, F., Schneider, F.D., van der Tol, C., Migliavacca, M. and Rascher, U. (2018) Remote Sensing of Plant-Water Relations: An Overview and Future Perspectives. Journal of Plant Physiology, 227, 3-19. https://doi.org/10.1016/j.jplph.2018.04.012

[34] Balafoutis, A., Beck, B., Fountas, S., Vangeyte, J., van der Wal, T., Soto, I., Gómez-Barbero, M., Barnes, A. and Eory, V. (2017) Precision Agriculture Technologies Positively Contributing to GHG Emissions Mitigation, Farm Productivity and Economics. Sustainability, 9, 1339. https://doi.org/10.3390/su9081339 